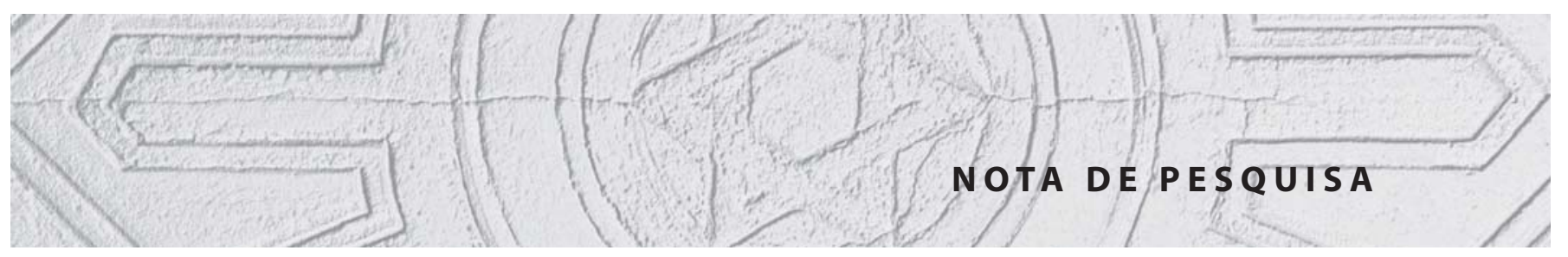

\title{
As insanas do Hospício Nacional de Alienados (1900-1939)
}

\author{
Insane women at the Hospício Nacional de Alienados \\ (1900-1939)
}

\author{
Cristiana Facchinetti \\ Pesquisadora da Casa de Oswaldo \\ Cruz/Fundação Oswaldo Cruz \\ Av. Brasil, 4365, s. 404 \\ 21040-900 Rio de Janeiro - RJ Brasil \\ cfac@coc.fiocruz.br
}

\section{Andréa Ribeiro}

Bolsista Tec-Tec-Faperj/Fundação Oswaldo Cruz

aoribeiro@gmail.com

\section{Pedro F. de Muñoz}

Bolsista Pibic-CNPq/Fundação

Oswaldo Cruz

cfac@coc.fiocruz.br
FACCHINETTI, Cristiana; RIBEIRO, Andréa; MUÑOZ, Pedro F. de. As insanas do Hospício Nacional de Alienados. História, Ciências, SaúdeManguinhos, Rio de Janeiro, v.15, supl., p.231-242, jun. 2008.

Este trabalho é um dos resultados de pesquisa de pós-doutoramento realizada entre 2004 e 2006 na Casa de Oswaldo Cruz/Fiocruz, com o apoio do CNPq e da Faperj, em que se buscou estabelecer uma cartografia das práticas psiquiátricas no Hospício Nacional de Alienados. O projeto tinha por objetivo levantar dados e analisar os processos de construção de diagnósticos, o tempo de internação e suas correlações. Para tanto, foram considerados os critérios: origens étnicas e nacionais, atividades profissionais, gênero, estado civil, idade, classe social, índice de mortalidade, origem geográfica e autoria dos prontuários. Neste texto restringimo-nos à relação entre gênero e loucura nas quatro primeiras décadas do século XX.

Palavras-chave: gênero; loucura; hospício; práticas psiquiátricas; Brasil.

FACCHINETTI, Cristiana; RIBEIRO, Andréa; MUÑOZ, Pedro F. de. Insane women at the Hospício Nacional de Alienados (1900-1939). História, Ciências, Saúde - Manguinhos, v.15, Suppl., p.231-242, June 2008 .

This study is one of the products of post-doctoral research carried out between 2004 and 2006 at the Casa de Oswaldo Cruz/Fiocruz, with the support of the research funding agencies $\mathrm{CNPq}$ and Faperi. The goal was to arrive at a cartography of psychiatric practices at the Hospício Nacional de Alienados (HNA) by surveying and analyzing the processes of constructing diagnoses and length of hospitalization and correlating these with the patient's ethnic and national origin, occupation, gender, marital status, age, social class, mortality rate, geographical origin, and other attributes. The present article limits itself to the issue of gender and madness during the first three decades of the twentieth century.

Keywords: gender; madness; asylum; psychiatric practices; Brazil. 
A história da institucionalização da psiquiatria no Brasil já foi alvo de numerosas pesquisas que se intensificaram a partir de meados da década de 1970, estimuladas pela revisão do campo psiquiátrico. Esse movimento antipsiquiátrico, que deu origem à Reforma Psiquiátrica ${ }^{1}$, foi influenciado pela arqueologia e genealogia foucaultianas. ${ }^{2}$ Desde a década de 1990 o tema vem perdendo espaço para pesquisas sobre um passado recente, voltadas para o processo de desinstitucionalização. Isso se explica, especialmente, pela dificuldade de acesso às fontes primárias, ou seja, pela dispersão institucional do antigo Hospício Nacional durante o século XX (criação de colônias e do Manicômio Judiciário, por exemplo, que foram redistribuindo os antigos prontuários do Hospital Nacional de Alienados (HNA) em novas instituições e produzindo novos documentos) e pela precária condição de higienização e organização do material nas diferentes instituições. Além disso, a municipalização das instituições de saúde do país, na década de 1980 (cf. Amarante, 1995; Tenório, jan.-abr. 2002; Tundis, Costa, 1994), aumentou a complexidade política do acesso às fontes.

A pesquisa por nós iniciada em 2006, com apoio Faperj/Fiocruz, apresenta dois objetivos. ${ }^{3}$ O primeiro, estritamente acadêmico, é investigar as práticas psiquiátricas no HNA, do período em que Juliano Moreira dirigiu o Hospício (1903-1930) até sua transferência para Engenho de Dentro (1938-1943). Pretendemos analisar a produção de regras narrativas, as transformações na compreensão da loucura e os modelos de modernidade que dão contorno às novas doentes mentais, apresentando suas subjetividades como o avesso do modelo ideal de mulher. Nossa estratégia foi priorizar os prontuários do Hospício, de modo a observar como se entrecruzam, na institucionalização da psiquiatria nacional, os diferentes modelos de saúde mental, de gênero e de referências teóricas.

Nosso segundo objetivo é desenvolver meios para fomentar a pesquisa na área. Para isso, estamos construindo uma Base de Dados de Prontuários e Similares, relativa ao período assinalado, com o objetivo de integrar virtualmente o maior número possível de documentos e de reunir informações dispersas em diferentes acervos. Ao disponibilizar fontes primárias e secundárias na Internet, esperamos estimular também a formação de novos mestres e doutores.

\section{Fontes e banco de dados}

Os prontuários e documentos similares, produzidos pelo antigo HNA, estão hoje dispersos em quatro instituições psiquiátricas do Rio de Janeiro. O acervo de prontuários do HNA, pertencente ao Ministério da Saúde, está sob a guarda do Instituto Municipal de Assistência à Saúde Nise da Silveira (IMASNS). Os acervos de livros de observação e de laudos psiquiátricos da Seção Lombroso do HNA e do Manicômio Judiciário, pertencentes ao estado do Rio de Janeiro, estão sob a guarda do Hospital de Custódia e Tratamento Psiquiátrico Heitor Carrilho (HCTPHC). Os acervos de prontuários do HNA e de fichas de observação da Colônia Juliano Moreira, pertencentes à Secretaria Municipal de Saúde, estão sob a guarda do Instituto Municipal de Assistência à Saúde Juliano Moreira (IMASJM). Finalmente, o acervo de livros de observação do HNA, pertencente à Universidade Federal do Rio de Janeiro (UFRJ), está sob a guarda do Instituto de Psiquiatria (Ipub). Esses materiais 
vêm sendo transpostos para uma base de dados que deverá alcançar, até o fim do primeiro semestre de 2008, cerca de quatro mil documentos clínicos, entre prontuários, livros e fichas de observações.

O formulário de preenchimento é composto por 38 campos. Os dois primeiros, número de registro e localização do acervo, destinam-se à identificação da fonte documental quanto ao acervo virtual criado (a própria base) e ao acervo físico consultado (sob a guarda das instituições parceiras). Os campos subseqüentes são: ano (de internação do paciente), instituição/seção (em que o paciente esteve internado), nome, nação/estado, classe, cor, sexo, constituição (física do paciente), temperamento, (data de) entrada, idade, estatura, estado civil, profissão, residência, procedência, requerente, diagnósticos (em número de três), médico (que assina o prontuário), diretor, (data de) alta, (data de) falecimento, causa mortis, médico de alta/falecimento, observações médicas (palavras-chave temáticas), outras identidades (diferentes nomes assumidos pelo paciente em diferentes internações) e transferências/reinternações. Há ainda outros quatro campos - delito, laudo, documentos anexos e observações do pesquisador -, que permitem ao pesquisador obter informações relevantes acerca dos internos, além das já disponíveis nos documentos clínicos analisados. Isso não significa que todos esses campos existam nos documentos originais, mas sim que os prontuários e similares contêm essas informações em seu corpo.

Além da contínua alimentação do banco, estamos desenvolvendo um índice de palavraschave de acordo com os Descritores em Ciências da Saúde (DeCS), vocabulário controlado trilíngüe, criado pela Bireme para facilitar a recuperação de informações contidas em artigos científicos, livros, anais de congressos, relatórios e outros materiais produzidos pelas ciências da saúde.

No que diz respeito à busca, será possível recuperar as informações contidas nos prontuários de três formas. A primeira, através dos DeCS, indicando o descritor na caixa de diálogo correspondente. A segunda, a partir de termos livres, criados pela equipe de pesquisadores, compondo um índice de temas não contemplados pelos DeCS. A terceira, pela busca livre, digitando-se na caixa de diálogo correspondente qualquer termo.

\section{Procedimentos teórico-metodológicos}

A experiência até agora acumulada permite-nos afirmar a importância do uso de documentos clínicos como fonte primária. Combinados com a leitura de textos psiquiátricos da época e em comparação com seu contexto histórico-cultural, tais documentos permitem que se tenha acesso ao cotidiano do hospital, a seus processos diagnósticos, terapêuticos etc.

Para a pesquisa sobre a relação entre gênero e loucura, alguns campos do banco de dados têm sido priorizados: gênero, classe, estado civil, temperamento, diagnóstico e tempo de internação, bem como referências a questões como comportamentos, órgãos sexuais e outros, considerados patológicos pelo pensamento médico (Dorlin, 2006). Além disso, foi feita uma seleção de alguns casos para análise e comparação quanto aos meios teóricos, retóricos e literários usados pelos psiquiatras para dar credibilidade a seus diagnósticos e suas terapêuticas ao tratarem de mulheres e de homens. 
Buscamos discutir os conceitos de loucura, sexualidade e gênero, de modo a poder escolher os casos que melhor trazem à tona as categorias que nos interessam investigar. Assim, a partir de Koselleck (2006), procuramos definir alguns significados. Uma de nossas primeiras atividades foi a delimitação de gênero e de sexualidade com base em Scott (jul.-dez. 1995), Dorlin (2006) e Foucault (1984), para a primeira categoria, e ainda Freud (1989) e Birman (1996), para a segunda. Para a contextualização no período, utilizamos periódicos psiquiátricos brasileiros da época ${ }^{4}$, literatura ${ }^{5}$ e artigos de jornais 6 . Delimitado e contextualizado o conceito, selecionamos os casos no banco de prontuários.

Os prontuários de pacientes femininos são cruzados com outras fontes primárias, tais como laudos da medicina legal e prontuários masculinos, de modo a ampliar nossa discussão sobre a categoria de gênero e sua relação com a loucura.

Apoiados nos conceitos de loucura advindos da história (Sadowsky, 1999; Certeau, 1982), da filosofia (Foucault, 1978) e da antropologia (Jenkins, sept. 1998), buscamos, por um lado, apreender os significados da loucura entre 1900 e 1939 como produto sociocultural, influenciado e determinado a um só tempo pela sociedade envolvente e pelo asilo, lugar de confinamento e, por outro lado, analisar a psiquiatria da época como técnica que configura um espaço de pensamento e que deriva de um fazer, uma prática científica. Nesse sentido, escolhemos alguns diagnósticos hegemônicos para mulheres e homens, bem como sinais freqüentes das desordens apresentadas, e analisamos as mudanças que sofreram ao longo das quatro décadas assinaladas.

A etapa seguinte trata da discussão sobre as variações semânticas e conceituais, sobre os 'não-ditos' e as disputas de que são alvos esses significados, confrontando tais variações com as mudanças sociais, políticas e científicas que ocorrem em idêntico contexto - sem esquecer de articular o papel social de mulheres e homens no processo de constituição do Brasil moderno. Para isso, apoiamo-nos nas proposições de Certeau (1987) e Koselleck (2006).

\section{Resultados parciais e discussões teóricas}

Perfil geral de pacientes

Desde as últimas décadas do século XIX, teve grande impacto o crescimento de alguns centros urbanos do país. O Rio de Janeiro, sede do governo no Império, conservou sua condição de eixo político e administrativo após a proclamação da República e ao longo de todo o período por nós estudado. A capital foi centro de grande atividade industrial, atraindo, até o início da década de 1930, operários, ex-escravos e trabalhadores de diversas regiões brasileiras e de outros países, que constituíram uma população diversificada e pobre na cidade do Rio de Janeiro.

Qualificados com freqüência de 'degenerados', esses indivíduos forneceram o contingente principal entre os internados do HNA, ajudando a consolidar, entre as elites, a imagem das classes trabalhadoras como perigosas. Não é, portanto, de estranhar que a internação de cerca de $94 \%$ dos pacientes tenha sido paga pelo governo do Distrito Federal. Além disso, mais de $96 \%$ chegavam ao asilo pelas mãos da polícia ou de instituições similares. As Seções Pinel e Esquirol, destinadas a alienados 'indigentes', como nos informa J. Moreira (1916), viviam apinhadas e representavam o alvo prioritário de assistência, já que 
"albergavam os piores representantes das classes mais desprotegidas da sociedade, com seus piores vícios e delinqüência".

Embora minoria no hospício (38,4\% no universo investigado), boa parte das mulheres internadas era 'parda' ou 'negra', fato que não surpreende quando se lêem os textos psiquiátricos da época e as alusões pejorativas feitas então à 'pequena África' e ao asilo como lugar social daquelas mulheres (cf. Lopes, 2000; Moura, 1983).

Entretanto, a análise dos materiais pesquisados vem trazendo algumas surpresas: a maioria dos internados do HNA no período, embora pobre, é constituída por homens brancos. ${ }^{7}$ Tal resultado contrasta com o que foi encontrado por Cunha (1986) no Juquery e aparentemente contradiz as referências à loucura na literatura consultada. Como é possível que a grande massa de 'degenerados' pobres da cidade fosse negra ou mestiça, se isso não se espelha no hospício? Ressalte-se que os dados de nosso universo de pesquisa condizem com dois artigos do renomado psiquiatra Henrique Roxo $(1904,1908)$, nos quais apresentase o quadro estatístico dos doentes internados no pavilhão de observação do HNA.

Nossa hipótese é que a psiquiatria nacional buscava ganhar credibilidade junto ao Estado e, para isso, precisava demonstrar que era capaz de curar os doentes. Assim, enquanto os casos agudos eram tratados no hospício, os casos crônicos que superlotavam o HNA eram mandados para as colônias - no caso dos homens, aqueles considerados mais refratários aos novos papéis sociais masculinos articulados aos valores do trabalho (Oliveira, 2004), fato que explicaria a maioria de homens brancos e trabalhadores no HNA.

Como o número de homens internados no HNA era maior, o número de colônias de alienados para homens destinadas aos tratamentos terapêuticos firmados no trabalho manufaturas, artesanatos etc. - era também mais expressivo (Colônia da Ilha do Governador, Colônia São Bento, Colônia Conde de Mesquita, Colônia Agrícola de Jacarepaguá) do que o número de colônias para mulheres (Colônia de Engenho de Dentro). Além disso, a primeira colônia feminina só foi fundada em 1911, ao passo que duas das colônias masculinas já estavam em funcionamento desde 1887. Assim, a diferença no número de homens mandados para as colônias poderia explicar a prevalência de homens brancos e de mulheres pardas e negras no HNA. O trabalho junto à Colônia Juliano Moreira permitirá, futuramente, verificar essa hipótese.

Além disso, tal como acontece hoje, as redes pessoais tendiam a favorecer o ingresso e o atendimento de pacientes. Assim, homens brancos, trabalhadores, ainda que pobres, tinham apoio de patrões e de outros contatos sociais que os auxiliavam na internação. Algumas cartas anexadas aos prontuários, escritas por pessoas que se responsabilizavam pelos pacientes, parecem indicar que essa é uma hipótese plausível. Entretanto nenhuma das suposições aqui apresentadas explica claramente a disparidade entre homens e mulheres quanto às diferenças de cor. A investigação em curso sobre as referências teóricas e ideológicas subjacentes às decisões diagnósticas e à internação de mulheres poderá fornecer os elementos necessários para esclarecer a questão.

Outro dado retirado do universo estudado até o momento (cerca de três mil prontuários) indica que a maioria das mulheres morria durante a internação (65\%), enquanto a maioria dos homens obtinha alta e deixava o hospital (56\%). A morte dos pacientes, no mais das vezes, era decorrente de doenças que grassavam no HNA: disenteria, enterite, enterocolite, 
tuberculose, desnutrição etc. Como as mulheres ficavam mais tempo internadas (698 dias, em média) que os homens (497 dias, em média) e eram sujeitas a um número de cirurgias significativamente maior (36\%) que os homens (29\%), sua estada no Hospício significava risco de vida bem superior. Dos pacientes operados, 69\% acabavam em óbito (a porcentagem é de $45 \%$ para os que não sofriam cirurgia).

Além disso, é significativa a diferença de tempo de internação entre os pacientes cujos prontuários continham alguma referência à sexualidade (779 dias, em média) e aqueles que passavam ao largo dessa questão (542 dias, em média). Cabe acrescentar que o número de mulheres com referências explícitas à sexualidade em seus prontuários chega a 19\%, ao passo que, no caso dos homens, esse número é de apenas 5\%. Aqui, novamente, se observa maior tempo de internação e maior probabilidade de óbito. Os pacientes que recebiam alta permaneciam bem menos tempo no hospital (cerca de 230 dias) do que os que acabavam por morrer durante a internação (cerca de 1.024 dias).

\section{Diagnósticos prevalentes}

A historiografia brasileira tem se esforçado para romper o silêncio que os diagnósticos ajudaram a criar, calando subjetividades e resistências por meio da medicalização dos comportamentos anti-sociais. Maria Clementina da Cunha (1996), por exemplo, trouxe nova luz à compreensão da realidade dos internos do Juquery, e Magali Engel (2001) fez o mesmo em relação ao Hospício Pedro II/Hospital Nacional. Na esteira desses estudos, buscamos investigar a experiência dos internos e internas do HNA, com o intuito de trazer à tona as diferenças de atribuição de diagnósticos e as conseqüências disso para a experiência e conformação das subjetividades. Trata-se de deslindar de que modo as mulheres internadas acabavam por se transformar no outro da ordem e da razão, e como suas experiências podem esclarecer quais eram os modelos ideais de cidadania em que dificilmente logravam acolhida. Trata-se, enfim, de tentar entender o que era a loucura no início do século XX e quais as implicações de pensar a inexistência de uma 'essência de loucura' em favor da investigação histórica sobre como ela foi nomeada, definida e tratada.

Com esses objetivos, buscamos compreender os motivos que levaram os alienistas do século XIX e psiquiatras do início do século XX a escolher certas palavras para descrever e explicar sinais e sintomas de insanidade. Consideramos que as observações dos médicos do HNA reproduziam um vocabulário, uma sintaxe e determinados pressupostos sobre o comportamento humano construídos pela medicina do Ocidente. Os sintomas mentais são, na maioria, variações quantitativas da ação ou da fala, e as descrições parecem ser fenomenológicas. No entanto, o exame da prática clínica nos mostra como a descrição final de um diagnóstico está marcada, por um lado, por sinais mais ou menos claros e, por outro, por códigos sociais, fato que demonstra que o psiquiatra é instruído culturalmente sobre como perceber uma desordem mental (Berrios, 1996).

O estudo das psicopatologias e de sua relação com os outros campos do banco ainda está em processo de elaboração. Separamos para análise os diagnósticos de histeria (prevalentes até a década de 1920), psicose maníaco-depressiva (prevalentes a partir da década de 1930), confusão mental e psicose periódica, por serem os mais comuns entre as mulheres internadas do HNA. Para os homens os diagnósticos mais freqüentes eram, nas 
primeiras duas décadas do século XX, sífilis, alcoolismo, demência precoce e, a partir da década de 1930, esquizofrenia, degeneração e paranóia.

Quanto aos sintomas e sinais selecionados, chamamos de 'sexo' uma variável que inclui todos os elementos relativos a gênero, sexo e sexualidade. Assim, escolhemos os casos que mencionam as seguintes ocorrências: aumento ou diminuição de mamas, ovários, útero e clitóris; modificação de sensibilidade nesses órgãos, bem como inflamações, purulências e 'corrimentos' advindos de gonorréias, sífilis, blenorragia, candidíase; variações menstruais, tanto no que diz respeito à menarca e à menopausa quanto à quantidade e periodicidade catamenial; problemas concernentes à gravidez, 'masturbação', 'ninfomania', 'safismo', 'recusa a entregar-se ao marido', nudez/exibicionismo e mesmo 'olhares lânguidos'. Do mesmo modo, outros casos selecionados tratam de questões que relacionamos a gênero, como por exemplo: mulheres que se recusam a usar saias ou vestuário feminino; que possuem 'rebeldia natural', as irritadiças, com crises de ira; que fogem de casa; que tentam se livrar dos filhos por aborto ou abandono; que abandonam seus maridos; que preferem a prostituição e a boemia ao casamento; que se recusam a casar e até mesmo que estudam em excesso.

Além desses 'sintomas' e 'sinais' que selecionamos para análise, o campo temperamento nem sempre preenchido pelos médicos - tem servido também para fundamentar a préseleção que fizemos, apoiada em Dorlin (2006). Segundo a autora, as teorias acerca do temperamento ajudaram a informar o gênero e as doenças femininas no século XX.

\section{Mulheres (loucas)}

A partir dos prontuários e documentos similares procurou-se responder à pergunta sobre o que era a loucura tipicamente feminina no início do século XX, no Rio de Janeiro. Nessa época, nem mesmo as mulheres burguesas das cidades se mantinham reclusas. Algumas se inseriam no mundo do trabalho, em que é possível identificar um nascente movimento feminista (Nunes, 1996). As novas atitudes colocavam em risco os ideais de esposa e mãe cuidadosamente construídos ao longo do século XIX e reproduzidos pelos psiquiatras no início do XX. No campo médico, as novas posturas femininas tiveram conseqüências: o mesmo discurso que produzira o ideal da mulher burguesa como modelo de subjetividade feminino passava a classificar como anomalia as particularidades desse gênero, criando novas estratégias para circunscrevê-lo ao modelo ideal (cf. Puech, abr.-jun. 1907; Roxo, 1928).

De fato, a crescente preocupação com a construção do país como nação moderna (e, naquele contexto, saudável) destacava a mulher como objeto de grande interesse para a medicina nacional. Isso acontecia desde o XIX, uma vez que a mulher, com sua prole, era a depositária do futuro da nação.

O material coletado para análise parece indicar que a visão dos psiquiatras da primeira década do século XX sobre o sexo feminino estava ainda profundamente impregnada de pressupostos do século anterior. As práticas formadas por essa visão continuavam a apontar o corpo das mulheres como mais predisposto a sofrer abalos mentais e morais, em decorrência de uma 'fraqueza natural', seja por sua natureza, seja por seu "inadequado processo civilizatório" (Roxo, 1928). As particularidades do sexo feminino eram, em geral, facilmente 
identificadas com os sinais de comportamento 'primitivo' e mais próximo ao selvagem. Como escreveu Foucault (1978), na medicina, teoria e prática terapêutica comunicam-se sempre em reciprocidade imperfeita. O universo da clínica é sempre mais estável, mais estruturado e conservador que as teorias, e seu desenvolvimento não costuma produzir renovações radicais.

Assim, com Dorlin (2006), propomos que a ciência médica foi fundamental na apreensão da diferença sexual desde a Antiguidade, tendo utilizado as categorias de saúde e de doença para definir o corpo feminino em contraste com o masculino, fazendo da mulher um ser fundamentalmente doente.

O conceito de temperamento foi utilizado pela medicina até o século XVII para designar a conformação interna dos corpos e suas diferenças. Segundo as representações originárias do corpus hipocrático, o corpo era composto por humores de diferentes qualidades e de equilíbrio variável. Essa concepção permitiu que, na Renascença, se alocassem os indivíduos em diferentes tipos que definiam sua predisposição patológica, transformando o corpo em um discurso capaz de sinalizar a natureza dos indivíduos, suas paixões, seu caráter, seus pensamentos, sua predisposição para doenças, vícios e virtudes (Dorlin, 2006).

O temperamento fleumático foi transformado no temperamento feminino típico. Tal nosologia permitiu configurar a diferença sexual dos corpos e justificar a desigualdade. As mulheres seriam frágeis em virtude de estarem seus corpos constantemente doentes e serem indomáveis. Isso explicava muitas das 'doenças femininas', cada vez mais associadas ao aumento ou à diminuição dos fluidos advindos do útero. Tais alterações seriam capazes de produzir visões, delírios, desejos, impulsos, febres etc. (Dorlin, 2006).

Segundo alguns autores (Dorlin, 2006; Laqueur, 2001), no século XVIII esse quadro foi fortemente modificado. Por influência das descobertas da anatomia e da importância que as mulheres adquiriram, em razão do papel fundamental que passava a ter a população para a prosperidade das nações, a procriação e a saúde materna tornaram-se questões cruciais. Nesse contexto, a saúde da mulher foi associada à imagem do corpo perfeitamente regulado, portanto mensurável, previsível e manipulável (cf. Rousseau, 1775). O interesse pela quantificação centrava-se especialmente na menstruação e na gravidez. Esta passou a ser vista como o grande trabalho da mulher, e a maternidade, sua principal característica (Laqueur, 2001).

Elaborava-se, então, uma nova configuração fisioanatômica da mulher, e suas predisposições mórbidas foram redefinidas. A nova visão sobre a mulher transformava sua fragilidade em saúde, já que suas doenças teriam origem na resistência a assumir sua natureza frágil e delicada. No processo, o temperamento fleumático deixou de ser a essência das mulheres, e os diferentes temperamentos femininos passaram a ser hierarquizados (Dorlin, 2006). No ápice dessa hierarquia, considerada modelo de saúde e encarnação mesma da feminilidade, estava a maternidade (Scott, jul.-dez. 1995).

Ao mesmo tempo, a doença passou a representar uma espécie de denúncia: o corpo da mulher passava supostamente a comprovar práticas ilícitas ou anormais, contrárias a sua natureza passiva e a sua capacidade de ceder aos movimentos da natureza sem a eles se opor (Roxo, 1918). Desse modo, comportamentos como a masturbação, o safismo, a abstinência, a coqueteria dos salões e o excesso de exposição a atividades excitantes passavam 
a ser delatados pelo corpo através de doenças como a histeria, a ninfomania e o esgotamento físico e psíquico (Roxo, 1904).

Assim, a natureza feminina fazia que as mulheres carecessem de maior controle para garantir sua normalidade, o que significava se tornarem esposa e mãe modelares. No hospício, encontramos justamente aquelas que fogem a esse padrão: são muito comuns 'sintomas' de desvios, que incluíam desde os 'olhares lânguidos' (IdHospital 131) de jovens à 'rebeldia natural' (IdHospital 16) de donas-de-casa. Em vista de tais sinais, até 1919, grande parte das mulheres era diagnosticada como histérica. A partir de 1920, os diagnósticos de histeria rareiam, chegando a menos de $2 \%$ na década de 1930 . Em compensação, a maior parte das mulheres passou a ser diagnosticada como maníaco-depressiva. Mas o que tais diagnósticos apontam?

De acordo com Roxo (1908), a histeria era causa de uma das maiores reincidências no hospital (18\%), por conta da instabilidade mental dessas pacientes. Para o autor, "as histéricas" seriam propensas a "estados hipnóides" e tinham um "olhar sonhador, voluptuoso e úmido". Ainda segundo Roxo (1907), elas apresentariam uma "inteligência que prejudica, dando recursos ao egoísmo, diversão do espírito, orgulho sem limites, malevolência, falta de compreensão completa dos deveres sociais", além de promover a simulação e a mentira "por fruto da imaginação exaltada e de alucinações", e por isso produziriam "intrigas", fazendo-se "de vítimas". Finalmente, eram marcadas por "extrema sugestionabilidade". Entre outros sintomas típicos encontrados nos prontuários com esse diagnóstico está a perda da força de vontade e a perversão moral (cf. Birman, 1978).

A loucura maníaco-depressiva, por sua vez, estava freqüentemente articulada aos períodos menstruais. Crises de raiva tornavam-se quase explosões de mania, carregadas de erotismo. Parece ser um pressuposto óbvio que a mania fosse resultante da hiperestesia ovariana, uterina e das mamas. Quanto ao delírio de ciúmes e ao alcoolismo, 'sinais patológicos' muito freqüentes, vinham quase sempre associados à menopausa, enquanto que o período melancólico estaria vinculado à chegada da menstruação (Maudsley, 1979; Puech, 1908; Sparano, 1916).

As marcas sociais do que se considerava loucura naquele período, bem como sua etiologia, nos oferecem não apenas um panorama do asilo e dos setores médico e psiquiátrico, mas também a representação de papéis sociais modelares, trazendo à tona uma discussão que exclui a loucura do campo da universalidade e passa a considerá-la a partir de um eixo histórico e cultural. Assim, em vez de loucura, haveria loucuras que se fariam marcar, ao menos parcialmente, como o avesso da normalidade em um contexto específico. E, no início do século XX, a loucura feminina no HNA andava de braços dados com a degeneração, vista como o avesso da civilização. 


\section{NOTAS}

${ }^{1}$ Ver, por exemplo, Amarante, 1982; Birman, 1978; Costa, 1989; Machado, 1978.

${ }^{2}$ Ver, como exemplo da arqueologia, Foucault, 1978, e da genealogia, Foucault ,1997.

${ }^{3} \mathrm{O}$ projeto de 2006 é constituído por três pesquisas integradas de pesquisadores da Casa de Oswaldo Cruz/Fiocruz: Ana Teresa Venancio, Cristiana Facchinetti (coord.) e Flávio C. Edler. As três pesquisas, que juntas abrangem um período de seis décadas, têm em comum o uso de documentos clínicos de diferentes instituições como fontes de pesquisa e a proposta de inclusão das fontes no banco de dados. As instituições pesquisadas são o HNA (Facchinetti, período: 1900-1939), o Manicômio Judiciário (Edler, período: 1930-1959) e a Colônia Juliano Moreira (Venancio, período: 1940-1969). Este texto trata apenas da pesquisa no HNA.

${ }^{4}$ Archivos Brasileiros de Psychiatria Neurologia e Sciencias Affins, Archivos Brasileiros de Psychiatria Neurologia e Medicina Legal e Archivos Brasileiros de Neuriatria e Psychiatria.

${ }^{5}$ Autores como Aluísio de Azevedo (1974), Machado de Assis (1971), Lima Barreto (1978), Mário de Andrade (1981) e Oswald de Andrade (1991) têm sido informantes fundamentais acerca das questões e papéis sociais de gênero no período.

${ }^{6}$ Tanto os artigos quanto os laudos estão nos acervos do Ipub e do HCTHC.

${ }^{7}$ Segundo a amostra, entre as pessoas denominadas de cor branca, quase 70\% são homens e apenas 30\%, mulheres. Entre os negros, 55,9\% são homens e 44,1\%, mulheres. Entre os pardos, 51,5\%, homens e $48,5 \%$, mulheres.

\section{REFERÊNCIAS BIBLIOGRÁFICAS}

AMARANTE, Paulo Duarte de Carvalho (Org.). Loucos pela vida: a trajetória da reforma psiquiátrica no Brasil. Rio de Janeiro: Ed. Fiocruz. 1995.

AMARANTE, Paulo Duarte de Carvalho. Psiquiatria social e colônias de alienados no Brasil (1830-1920). Dissertação (Mestrado) - Instituto de Medicina Social, Universidade do Estado do Rio de Janeiro, Rio de Janeiro. 1982.

ANDRADE, Mário de.

Amar, verbo intransitivo - idílio. Belo Horizonte: Villa Rica. 1981.

ANDRADE, Oswald de.

Santeiro do Mangue e outros poemas. São Paulo: Globo; Secretaria de Estado da Cultura. 1991.

ASSIS, Machado de.

Dom Casmurro. São Paulo: Ática. 1971.

AZEVEDO, Aluísio de.

O cortiço. São Paulo: Ática. 1.ed., 1890. 1974.

BARRETO, A.H. de Lima.

Clara dos Anjos. São Paulo: Brasiliense. 1978.

BERRIOS, German E.

A historia dos sintomas mentais: psicopatologia descritiva desde o século XIX. Cambridge: Cambridge University Press. 1996.

BIRMAN, Joel.

Por uma estilística da existência. São Paulo: Ed. 34. 1996.
BIRMAN, Joel.

A psiquiatria como discurso da moralidade. Rio de Janeiro: Graal. 1978.

CERTEAU, Michel de.

Histoire et psychanalyse: entre science et fiction. Paris: Gallimard. 1987.

CERTEAU, Michel de. A escrita da história. Rio de Janeiro: Forense Universitária. 1982.

COSTA, Jurandir Freire.

História da psiquiatria no Brasil: um corte ideológico. Rio de Janeiro: Xenon. 1989.

CUNHA, Maria Clementina Pereira.

O espelho do mundo: Juquery, a história de um asilo. Rio de Janeiro: Paz e Terra. 1986.

DORLIN, Elsa.

La matrice de la race: généalogie sexuelle et coloniale de la nation française. Paris: La Découverte. 2006.

ENGEL, Magali Gouveia.

Os delírios da razão: médicos, loucos e hospícios (Rio de Janeiro, 1830-1930) Rio de Janeiro: Ed. Fiocruz. (Col. Civilização e Loucura). 2001.

FOUCAULT, Michel.

Vigiar e punir: nascimento da prisão. Petrópolis: Vozes. 1997. 
FOUCAULT, Michel.

História da sexualidade II: o uso dos prazeres. Rio de Janeiro: Graal. 1984

FOUCAULT, Michel.

História da loucura na idade clássica. (1961) São Paulo: Perspectiva. 1978.

FREUD, Sigmund.

Três ensaios em teoria da sexualidade. (EBP, v.VII). Rio de Janeiro: Imago. 1. ed., 1905. 1989.

JENKINS, Janis.

Diagnostic criteria for schizofrenia and related psychotic disorders: integration and suppression of cultural evidence in DSM-IV. Transcultural Culture, Montreal, v.35, n.3, p.357-376. sept. 1998.

\section{KOSELLECK, Reinhart}

Futuro passado: contribuição à semântica dos tempos históricos. Rio de Janeiro:

Contraponto. p.191-197. 2006.

LAQUEUR, Thomas.

Inventando o sexo: corpo e gênero dos gregos a Freud. Rio de Janeiro: Relume Dumará. 2001.

LOPES, Antonio Herculano (Org.).

Entre Europa e África: a invenção do carioca. Rio de Janeiro: Topbooks. 2000.

MACHADO, Roberto et al.

Danação da norma: medicina social e constituição da psiquiatria no Brasil. Rio de Janeiro: Graal. p.375-492. 1978.

\section{MAUDSLEY, Henry.}

The pathology of mind: a study of its distempers, deformities and disorders. London: Julian Friedman Publ. 1.ed., 1879. 1979.

MOREIRA, Juliano.

Relatório da Diretoria Geral da Assistência a Alienados, enviado ao Ministério da Justiça em 10.3.1916. In: Relatório I dos anos de 1915 e 1916 apresentado ao Presidente da República pelo Ministério da Justiça. p. 62 Disponível em: http://brazil.crl.edu/bsd/bsd/u2322/ 000001.html. Acesso em: 4 mar. 2008. 1916.

MOURA, Roberto.

Tia Ciata e a pequena África no Rio de Janeiro. Rio de Janeiro: Instituto Nacional de Música/ Fundação Nacional de Arte. 1983.

NUNES, Silvia Alexin.

Entre a cruz e a caldeirinha, com o diabo no corpo. Tese (Doutorado em Saúde Coletiva) -

Universidade do Estado do Rio de Janeiro, Rio de Janeiro. 1996.

OLIVEIRA, Edmar de Sousa.

O Engenho de Dentro do lado de fora: o território como um engenho novo. Monografia
(Especialização de Gestão em Saúde) Fundação João Goulart, Rio de Janeiro. 2004.

PUECH, Luiz M. de Rezende. Considerações sobre a terapêutica cirúrgica na alienação mental. Archivos Brasileiros de Psychiatria, Neurologia e Medicina Legal, Rio de Janeiro, ano 4, n.1, 2. 1908.

PUECH, Luiz M. de Rezende. Gynecologia e alienação mental. Archivos Brasileiros de Psychiatria, Neurologia e Sciencias Affins, Rio de Janeiro, ano 3, n.2, p.352-375. abr.-jun. 1907.

ROUSSEAU, Jean-Jacques.

Système physique et moral de la femme, au tableau philosophique de la constitution, de l'état organique, du tempérament, des moeurs et des fonctions propres au sexe. Paris: Vincent. 1775.

ROXO, Henrique de Brito Belford.

Perturbações nervosas e mentaes que se observam nas doenças do útero e dos ovários. Tribuna Médica, Rio de Janeiro, ano 32, n.16, p.205-208. ago. 1928.

ROXO, Henrique de Brito Belford.

Estudo clínico da confusão mental (psychoses infecciosas e psychoses auto-tóxicas. Annaes da Faculdade de Medicina do Rio de Janeiro, Rio de Janeiro, ano 2, p.83-104. 1918.

ROXO, Henrique de Brito Belford.

Causas de reinternação de alienados no Hospício Nacional. Archivos Brasileiros de Psychiatria, Neurologia e Medicina Legal, Rio de Janeiro, ano 6, n.1-2, p.403-415. 1908.

ROXO, Henrique de Brito Belford. Dos estados mentaes nas grandes nevroses. Archivos Brasileiros de Psychiatria, Neurologia e Sciencias Affins, Rio de Janeiro, ano 3, p.247263. 1907.

ROXO, Henrique de Brito Belford.

Perturbações mentais nos negros do Brasil. Brazil-Medico, v.15-19, n.17, p.156-192. 1904.

SADOWSKY, Jonathan.

Imperial Bedlam: institutions of madness in colonial southwest Nigeria. Berkeley: University of California Press. 1999.

SCOTT, Joan.

Gênero: uma categoria útil de análise histórica. Educação \& Realidade. Mulher e educação, Porto Alegre, v.16, n.2, p.5-22. Número especial organizado por Eliane M.T. Lopes (UFMG) e Guacira Lopes Louro (UFRGS). jul.-dez. 1995.

SPARANO, Luiz.

O sexo em patologia (a questão feminina). Tese Faculdade de Medicina do Rio de Janeiro, Rio de Janeiro. 1916. 
TENÓRIO, Fernando.

A reforma psiquiátrica brasileira, da década de 1980 aos dias atuais: história e conceito.

História, Ciências, Saúde - Manguinhos, Rio de Janeiro, v.9, n.1, p.25-59. jan.-abr. 2002.

\section{PERIÓDICOS}

Archivos Brasileiros de Neuriatria e Psychiatria. Rio de Janeiro, 1920-1957.

Archivos Brasileiros de Psychiatria, Neurologia e Medicina Legal. Rio de Janeiro, anos 4-14, 1908-1918.
TUNDIS, Silvério Almeida; COSTA, Nilson do Rosário (Org.).

Cidadania e loucura: políticas de saúde mental no Brasil. Petrópolis: Vozes. p.15-74. (Col. Saúde e Realidade Brasileira). 1994.

Archivos Brasileiros de Psychiatria, Neurologia e Sciencias Affins. Rio de Janeiro, anos 1-3, 1904-1907. 